\title{
Prototipe Sistem Peringatan Dini Kebakaran Hutan Berbasis Parameter Cuaca
}

\author{
Chinthya Margaretta S ${ }^{1}$, Hapsoro Agung Nugroho ${ }^{2^{*}}$ \\ ${ }^{1}$ Stasiun Klimatologi Jambi, Jl. Raya Jambi-Muara Bulian KM.18 Jambi 36363, Indonesia \\ ${ }^{2}$ Sekolah Tinggi Meteorologi Klimatologi dan Geofisika, Jl. Perhubungan I No.5 \\ Tangerang Selatan 15221, Indonesia \\ * Penulis Penanggungjawab. E-mail: hapsoro.agung@bmkg.go.id \\ Hp: 081805582856
}

\begin{abstract}
ABSTRAK
Sistem peringatan dini kebakaran hutan memiliki peranan penting untuk mengendalikan secara dini kerusakan hutan. Badan Meteorologi Klimatologi dan Geofisika mempunyai tugas pokok, salah satunya yaitu memberikan peringatan dini kebakaran hutan menggunakan metode Fire Danger Rating System (FDRS) dimana data parameter cuaca sebagai masukan, masih terbatas pada lokasi tertentu. Penelitian ini merancang dan membangun prototipe yang menghasilkan skala Fine Fuel Moisture Code (FFMC) sebagai tingkat kemudahan terjadinya kebakaran di suatu lokasi. Perancangan prototipe ini menggunakan mikrokontroler ATMega328, sensor suhu dan kelembaban udara DHT22, penakar hujan jenis tipping bucket, sensor arah dan kecepatan angin JL_FS2, dan micro SD Card sebagai penyimpan data. Hasil kalibrasi sensor menunjukkan adanya selisih nilai sensor yang telah memenuhi nilai toleransi dari World Meteorological Organization (WMO). Pengujian setiap sensor menghasilkan nilai standar deviasi kurang dari 2.5 dengan rata- rata selisih pada sensor suhu $\pm 0.5^{\circ} \mathrm{C}$, kelembaban relatif $\pm 6 \%$, dan kecepatan angin $\pm 2 \mathrm{~m} / \mathrm{s}$. Setiap data yang diolah dapat ditampilkan dan disimpan secara otomatis oleh sistem. Sistem menampilkan secara realtime dan memberikan informasi peringatan dini kebakaran hutan.
\end{abstract}

65 | Copyright @ 2017, Wahana Fisika, e-ISSN:2549-1989 
Kata Kunci : Kebakaran Hutan; FDRS; FFMC; Tipping Bucket

\begin{abstract}
Forest fire early warning system has an important role for the control of early damage to the forest. Indonesia Agency of Meteorology Climatology and Geophysics had a duty, one that is giving early warning forest fires using the method of Fire Danger Rating System (FDRS) where weather data as the input parameters, are still limited on site certain. The study design and build a prototype that generates scale Fine Fuel Moisture Code (FFMC) as the level of ease the onset of fire in any given location. This prototype design using the ATMega328 microcontroller, sensor temperature and humidity DHT22, tipping bucket type of rain gauge, direction and wind speed sensor JL_FS2, and micro SD Card as the data storage. The results showed a difference in sensor calibration value of sensor meets the tolerance values of the World Meteorological Organization (WMO). Test each sensor shows a value less than 2.5 standard deviation by the average difference in temperature sensors $+0.5{ }^{\circ} \mathrm{C},+6 \%$ relative humidity, and wind speed +2 $\mathrm{m} / \mathrm{s}$. Data can be displayed and stored automatically by the system. The system displays in realtime and provide early warning information forest fires.
\end{abstract}

Keywords : Forest Fire; FDRS; FFMC; Tipping Bucket

\section{Pendahuluan}

Kebakaran hutan dan lahan (karhutla) merupakan salah satu permasalahan lingkungan yang cukup mendapat perhatian dari berbagai pihak. Karhutla terjadi hampir setiap tahun seiring dengan datangnya awal musim kemarau yang menyebabkan kekeringan. Fenomena alam tersebut memicu pembakaran hutan secara sengaja oleh manusia yang bertujuan untuk pembukaan lahan baru. Badan Meteorologi Klimatologi dan Geofisika (BMKG), Lembaga Penerbangan dan Antariksa Nasional 
(LAPAN), dan Badan Pengkajian dan Penerapan Teknologi (BPPT) merupakan instansi yang bertanggung jawab dalam manajemen pengendalian kebakaran hutan [1]. Data dan informasi yang dihasilkan oleh instansi pemerintah ini diperlukan dalam upaya pencegahan, terutama dalam kegiatan peringatan dini terjadinya kebakaran hutan

Sistem peringatan dini karhutla sangat penting untuk memberikan warning dan menghindari bencana lainnya yang diakibatkan oleh karhutla. Sistem dimaksudkan supaya masyarakat dan pihak terkait mendapat informasi lebih awal terkait karhutla, sehingga antisipasi kebakaran dapat dilakukan secara cepat dan tanggap. Sistem bertujuan memberikan peringatan dini potensi kebakaran yang terjadi di lokasi tersebut. Beberapa penelitian telah merancang sistem peringatan dini kebakaran hutan diantaranya memanfaatkan data titik panas menggunakan satelit [2], merancang bangun dengan sensor suhu [3] dan menggunakan sensor deteksi gas dan asap [4].
Salah satu metode yang digunakan dalam penentuan potensi karhutla dengan nilai FDRS yang didapat dengan masukan data parameter cuaca hasil pengamatan. Saat ini FDRS terkendala oleh kerapatan stasiun pengamatan cuaca milik BMKG yang mempengaruhi keakuratan interpolasi untuk pembuatan peta FDRS seperti yang ditunjukan pada Gambar 1. Penelitian ini melakukan perancangan sistem peringatan dini kebakaran hutan menggunakan metode FDRS dengan menggunakan data parameter cuaca realtime pada suatu lokasi. Parameter cuaca yang dibutuhkan seperti suhu dan kelembaban, curah hujan, dan kecepatan angin. Data parameter cuaca tersebut didapat dari sensor yang dihubungkan ke mikrokontroler. Mikrokontroler mengolah data berdasarkan pengukuran kemudian bila mencapai ambang batas tertentu sesuai dengan indeks, sistem akan memberikan informasi peringatan dini kebakaran hutan kepada petugas ataupun pihak yang terkait untuk segera diteruskan ke masyarakat. 


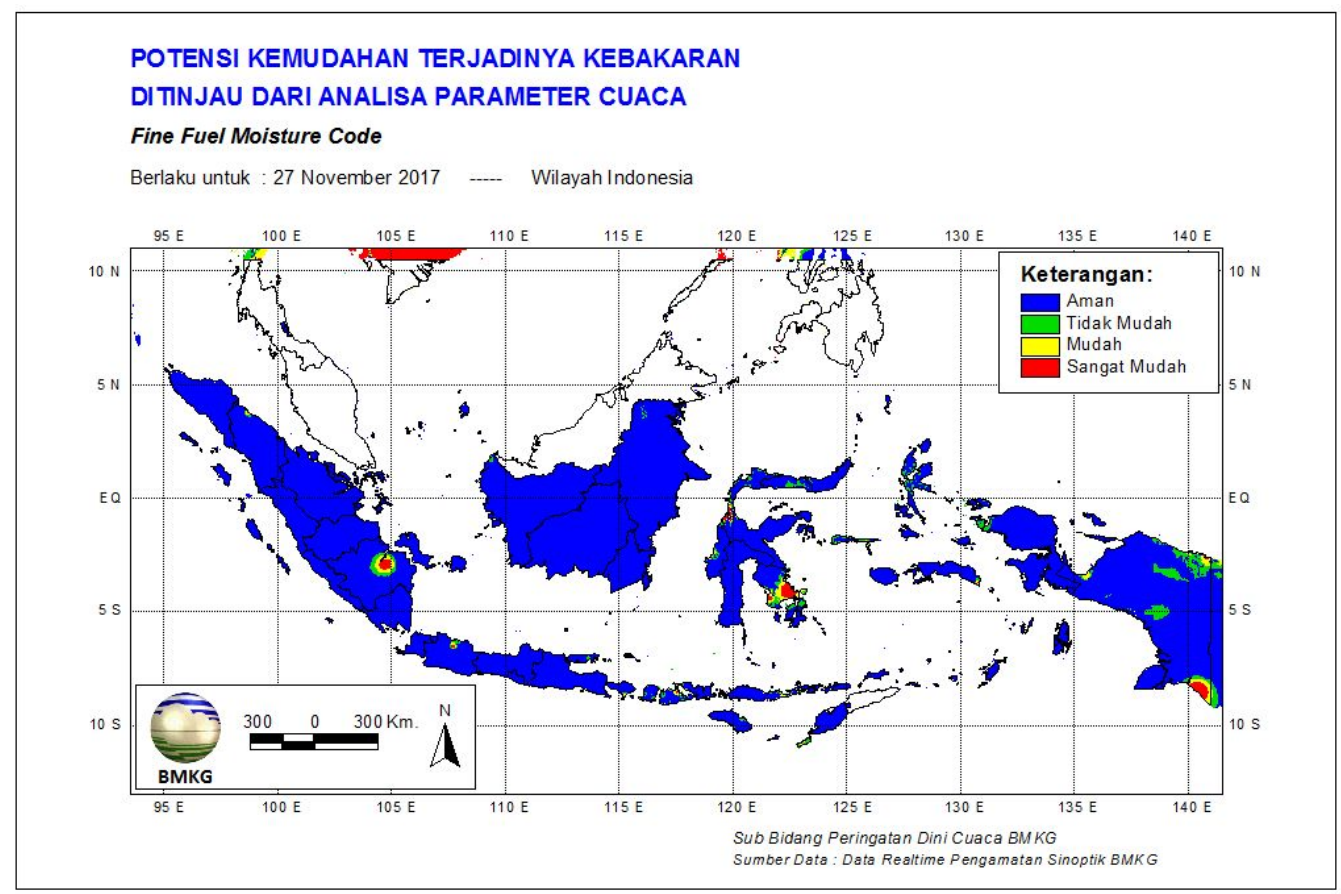

Gambar 1. Peta potensi kebakaran hutan

\section{Bahan dan Metode}

\subsection{Kebakaran Hutan}

Kebakaran hutan menurut Peraturan Menteri Kehutanan Nomor 12 tahun 2009 yaitu suatu keadaan dimana hutan dilanda api sehingga mengakibatkan kerusakan hasil hutan yang menimbulkan kerugian ekonomis dan lingkungan. Penyebab kebakaran hutan di Indonesia umumnya akibat dari aktivitas manusia. Pemanfaatan kondisi alam yang kering untuk pembukaan lahan, peremajaan hutan, maupun pengendalian hutan merupakan faktor dominan terjadinya kebakaran hutan. Menurut Hernandez, dkk
[5] parameter cuaca mempengaruhi bagaimana, dimana, kapan kebakaran hutan dapat terjadi. Faktor cuaca sering disebut sebagai cuaca kebakaran (fire weather) yaitu sifat-sifat cuaca yang mempengaruhi terjadinya kebakaran. Sifat cuaca tersebut berkaitan bahwa cuaca dan iklim mempengaruhi kebakaran hutan.

\subsection{Fire Danger Rating System}

Sistem FDRS merupakan sistem prediksi kebakaran hutan untuk mengetahui level bahaya potensi terjadinya kebakaran dan sebarannya [6]. Sistem penentuan tingkat bahaya kebakaran hutan didasarkan pada pengetahuan ilmiah tentang potensi awal 
terjadi kebakaran yang diolah dari hasil pengamatan operasional. Dasar FDRS yang dikembangkan di Indonesia adalah sistem Fire Weather Index (FWI). Parameter cuaca yang mempengaruhi nilai FWI yaitu suhu, kelembaban relatif, kecepatan angin, dan hujan pada siang hari [7]. Tiga komponen primer FWI antara lain: Fine Fuel Moisture Code (FFMC), Duff Moisture Code (DMC), dan Drought Code (DC) seperti pada Gambar 2. Skala FFMC merupakan indikator kemudahan penyulutan api dan kobaran api oleh bahan bakar halus yang dihubungkan dengan pengaruh cuaca pada hari sebelumnya. Sistem FDRS menyediakan nilai potensi kebakaran berdasarkan parameter data cuaca yang dihitung dari titik pengamatan yang tersebar di Indonesia. FWI menggambarkan tingkat kesulitan pengendalian kebakaran hutan yang ditinjau dari parameter cuaca dan iklim [8]. Skala FFMC dan FWI yang dikeluarkan oleh BMKG mewakili produk MEWS dalam menangani karhutla. Skala FFMC memiliki nilai skala tertentu yang diklasifikasikan dalam skala rendah hingga ekstrem [9].

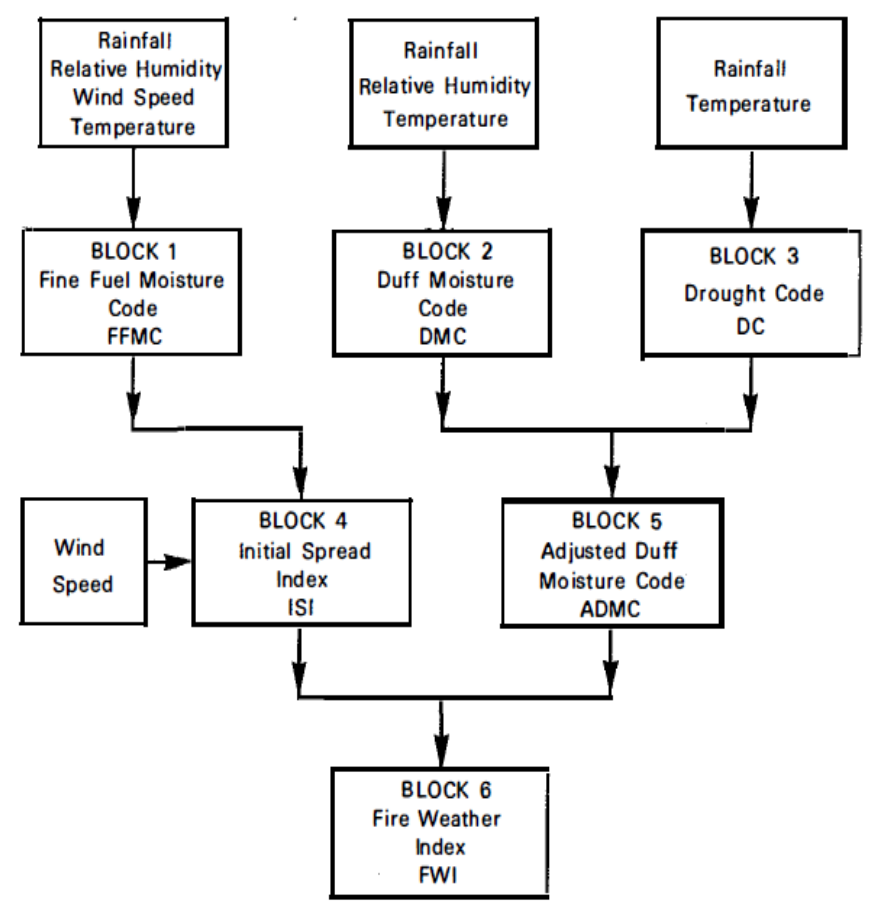

69 | Copyright @ 2017, Wahana Fisika, e-ISSN:2549-1989 
Gambar 2. Blok diagram FWI

Indeks FFMC diklasifikasikan dalam penyulutan api menjadi kebakaran. skala rendah, sedang, tinggi, hingga Penjabaran skala FDRS seperti ekstrem dan menjadi indikator potensi ditunjukan pada Tabel 1.

Tabel 1. Interval nilai skala FFMC

\begin{tabular}{|c|c|c|}
\hline Skala & Interval & Interpretasi \\
\hline Rendah & $0-36$ & Kemungkinan terpicu api sangat rendah. \\
\hline Sedang & $36-69$ & $\begin{array}{l}\text { Kemungkinan api terpicu pada daerah kering dan terbatas } \\
\text { daerah perambatan. }\end{array}$ \\
\hline Tinggi & $69-83$ & $\begin{array}{l}\text { Bahan bakar dapat dipicu api sedang dan berintensitas } \\
\text { tinggi. }\end{array}$ \\
\hline Ekstrem & $>83$ & $\begin{array}{l}\text { Keadaan kemarau parah dan adanya kondisi kebakaran } \\
\text { yang berbahaya. }\end{array}$ \\
\hline
\end{tabular}

\subsection{Perancangan Sistem}

Bagian utama pada sistem ada tiga yaitu input, pengolah data, dan output. Input merupakan data masukan seperti pada Gambar 3 dalam hal ini data berupa besaran fisis yang diukur oleh sensor. Sensor memberikan masukan data ke mikrokontroler. Mikrokontroler sebagai pusat pengolahan data berfungsi memproses data yang masuk dan mengendalikan proses-proses yang terjadi pada sistem. Mikrokontroler memiliki port sebagai penghubung sensor ke mikrokontroler dan komunikasi dari mikrokontroler ke display. Output m yang telah diolah di mikrokontroler dan ditampilkan pada PC maupun disimpan di micro SD card. Sistem FDRS menggunakan beberapa parameter pengamatan cuaca seperti pengukuran suhu dan kelembaban relatif menggunakan sensor DHT22, pengukuran curah hujan menggunakan penakar hujan tipping bucket, dan pengukuran kecepatan angin menggunakan sensor DFRobot JL-FS2. Setiap sensor dihubungkan ke mikrokontroler ATMega328 melalui port yang terdapat di minimum sistem. Sensor, Real Time Clock (RTC), micro SD card 
memperoleh sumber catu daya dari adaptor yang dihubungkan melalui minimum sistem. Mikrokontroler mengolah data sensor untuk menghasilkan suatu indeks. Micro SD card menyimpan data sensor dan indeks setiap 10 menit sebagai representasi harian FDRS. Interface menampilkan data berupa indeks FDRS dan data parameter cuaca seperti suhu, kelembaban relatif, curah hujan, dan kecepatan angin. Interface dalam bentuk Graphic User Interface mengeluarkan peringatan berupa pop-up message ketika indikator indeks FDRS melebihi batas wajar atau bernilai tinggi hingga ekstrem. Peringatan berupa jendela teks peringatan yang ditampilkan pada media antarmuka.

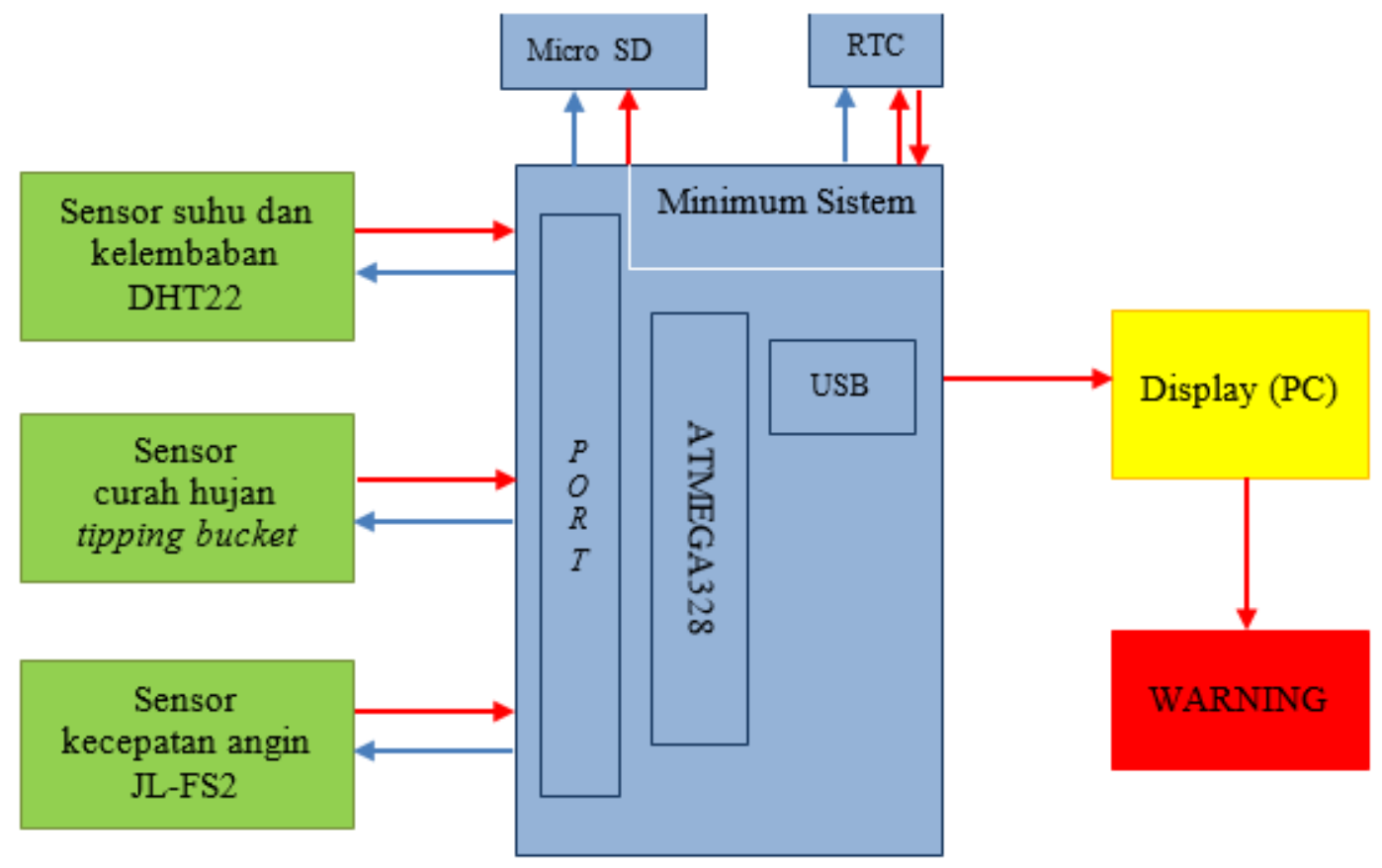

\section{Keterangan:}

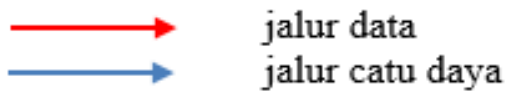

Gambar 3. Blok diagram perancangan system 


\section{Hasil dan Pembahasan}

Pengujian sistem FDRS menggunakan beberapa metode yaitu metode kalibrasi dan simulasi. Metode kalibrasi berfungsi untuk mengetahui kedekatan nilai keluaran dari sistem terhadap standar ukur dan mengetahui kehandalan bahwa sistem laik beroperasi. Metode simulasi bertujuan untuk mengetahui kinerja alat dengan meningkatkan kondisi cuaca di sekitar sistem. Analisis hasil pengujian sistem menggunakan beberapa metode statistika yang bertujuan untuk mengolah data pengujian di laboratorium dan pengujian sistem dengan alat observasi.

Rata-rata nilai koreksi kalibrasi sensor suhu DHT22 pada set point $20{ }^{\circ} \mathrm{C}, 30{ }^{\circ} \mathrm{C}$, dan $40{ }^{\circ} \mathrm{C}$ setelah dikalibrasi sebesar $0,01{ }^{\circ} \mathrm{C} ; 0,02{ }^{\circ} \mathrm{C}$; dan $0,01{ }^{\circ} \mathrm{C}$. Hasil koreksi kalibrasi untuk kelembaban menunjukkan nilai koreksi masingmasing set point yaitu $40 \%$, 60\%, dan $80 \%$ sebesar 0,38 \%; 0,37 \%; dan 0,28 \%. Sedangkan untuk hasil kalibrasi sensor penakar hujan menunjukan bahwa sensor bekerja dengan baik tanpa adanya kehilangan sinyal data (loss signal) maupun sinyal ganda (cloning signal). Hasil pengukuran terkoreksi kecepatan angin menunjukkan nilai koreksi masingmasing set point yaitu $2 \mathrm{~m} / \mathrm{s}, 7 \mathrm{~m} / \mathrm{s}$, dan $10 \mathrm{~m} / \mathrm{s}$ sebesar $0,05 \mathrm{~m} / \mathrm{s} ; 0,28 \mathrm{~m} / \mathrm{s}$; dan $0,065 \mathrm{~m} / \mathrm{s}$. Rata- rata nilai koreksi tersebut masuk dalam nilai toleransi WMO dalam menyediakan data kecepatan angin. Sensor JL-FS2 pada penelitian ini memiliki nilai yang cukup linier. Pengujian dilakukan dengan membandingkan kebenaran informasi sistem dengan data yang telah ada dengan jalan memberi perlakuan khusus kepada setiap parameter cuaca. Kesesuaian data bertujuan untuk mengetahui bahwa sistem yang dirancang menghasilkan data yang sesuai dengan pengolahan data FDRS milik BMKG. Histori data yang digunakan pada penelitian ini yaitu data perhitungan FWI Kabupaten Jambi pada tanggal 15 April 2005 sesuai pada Tabel 2. 
Wahana Fisika, 2(2), 2017. 65 - 75

http://ejournal.upi.edu/index.php/wafi

e-ISSN : 2594-1989

Tabel 2. Data FWI untuk indeks FFMC Kabupaten Jambi pada April 2005

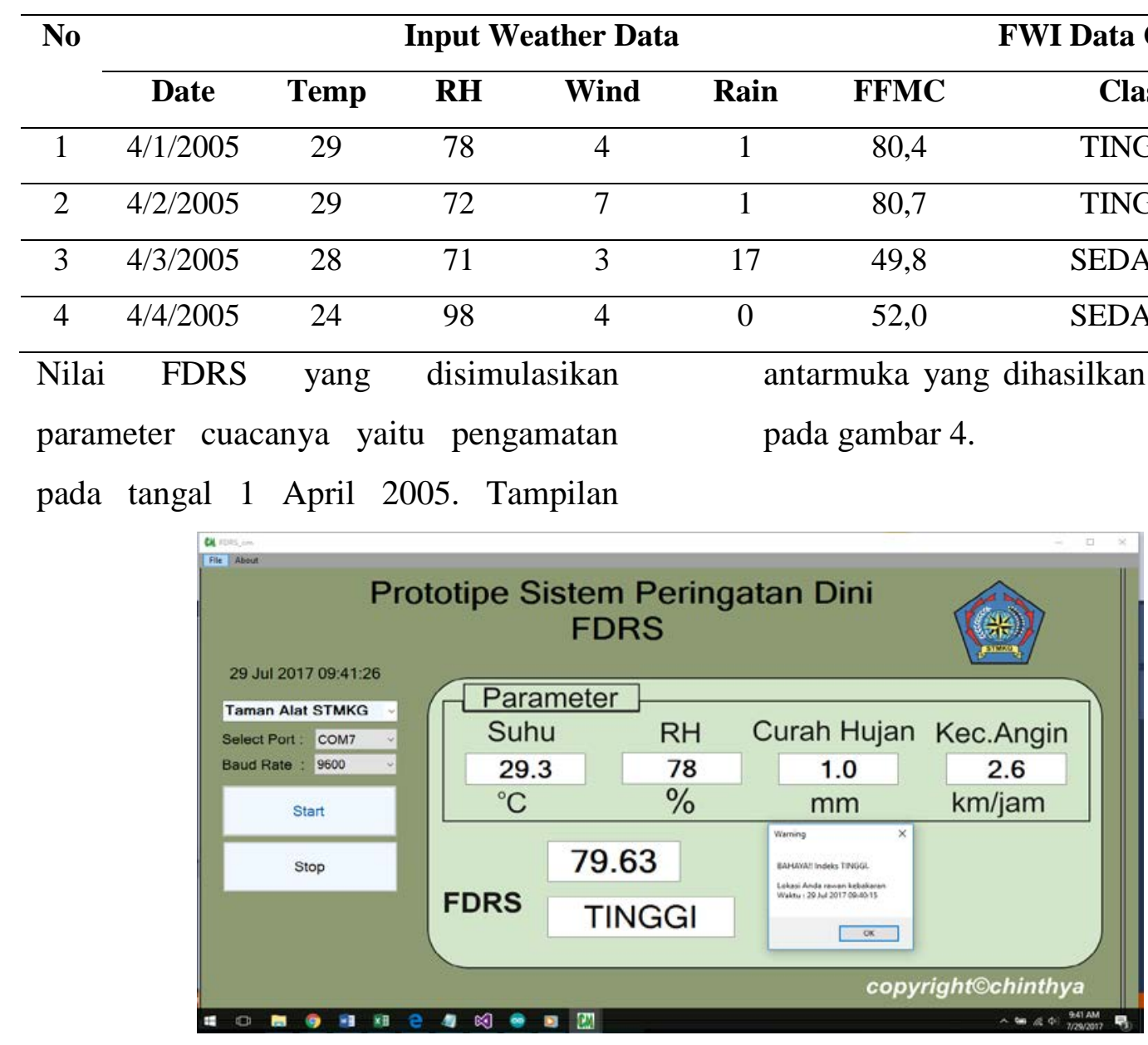

Gambar 4. Tampilan antarmuka simulasi data cuaca tanggal 1 April 2005

Gambar 5 merupakan pengaplikasian

sistem di lapangan pada siang hari dan

malam hari saat pengujian. Rangkaian

sistem secara keseluruhan berupa logger dan tiang dirancang sedemikan rupa untuk memudahkan sistem bekerja secara benar. 


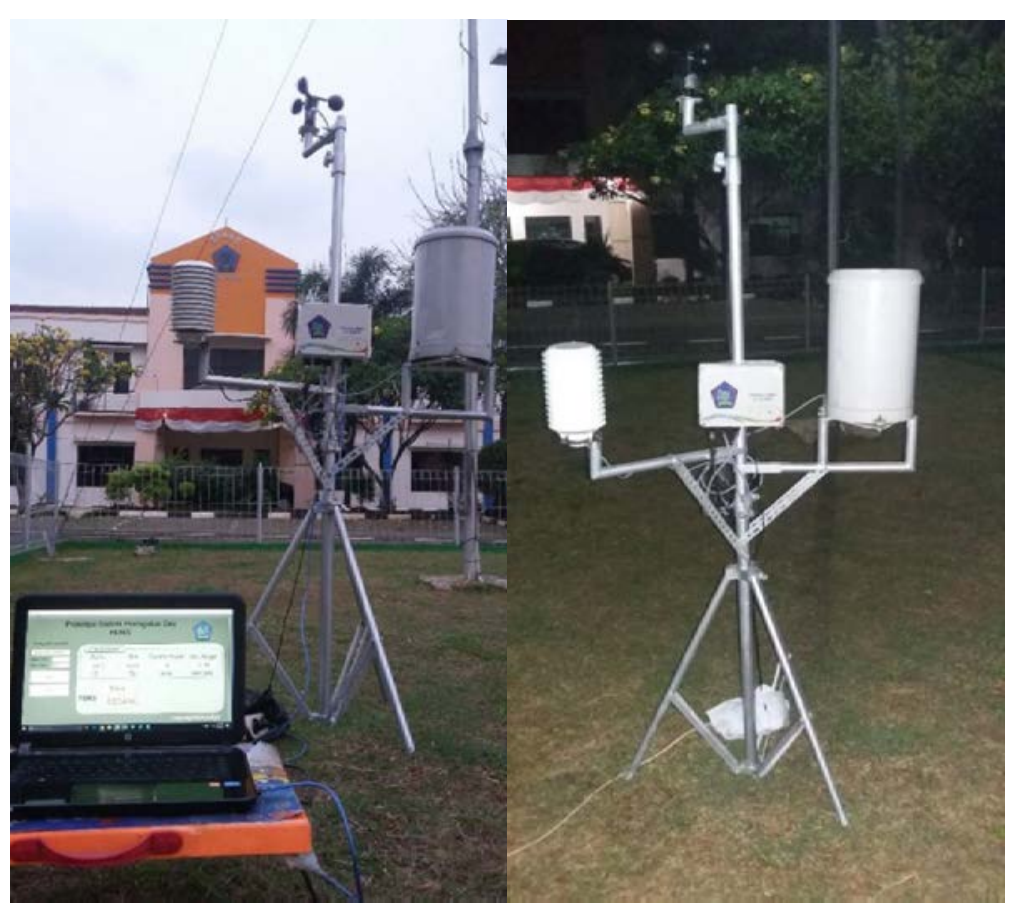

Gambar 5. Tampilan keseluruhan sistem saat pengujian

\section{Simpulan}

Sistem dapat memberikan informasi secara real-time potensi kebakaran hutan dan lahan pada lokasi yang tidak tercakup pengamatan cuaca sesuai dengan standar indeks potensi kebakaran hutan. Prototipe diuji melalui beberapa tahap, sehingga didapatkan informasi yang cepat dan sesuai yang diharapkan. Pengembangan sistem diperlukan agar beroperasi lebih baik kedepannya, seperti sistem masih menggunakan komunikasi kabel serial, untuk pengembangan selanjutnya disarankan menggunakan komunikasi nirkabel. Sistem ini juga dapat dikembangkan dengan menambahkan peta wilayah potensi terdampak, sehingga dapat dimonitoring lebih luas jangkauan kebakaran hutannya.

\section{Ucapan Terima Kasih}

Penulis mengucapkan terima kasih kepada Sekolah Tinggi Meteorologi Klimatologi dan Geofisika yang telah memberi dukungan sarana terhadap penelitian ini.

\section{Referensi}

1. Adinugroho, W. C., \& Suryadiputra, I. (2003). Strategi Pencegahan 
Kebakaran Hutan dan Lahan

Gambut, 1-6.

2. Roy, P. S. (2003). Forest Fire and Degradation Assessment Using Satellite Remote Sensing and Geographic Information System. Satellite Remote Sensing and GIS Applications in Agricultural Meteorology, 361-400.

3. Chandrasekharan, R. Q. V. P. Forest Fire Detection Using Temperature Sensors Powered by Tree and Auto Alarming Using GSM. IJRSI 2(3) 23-28 II, 23-28 (2015).

4. Krüll, W., Tobera, R., Willms, I., Essen, H., \& Von Wahl, N. (2012). Early Forest Fire Detection and Verification Using Optical Smoke, Gas and Microwave Sensors. Procedia Engineering, 45, 584-594. https://doi.org/10.1016/j.proeng.2012 .08 .208

5. Hernandez, C., Drobinski, P., \& Turquety, S. (2015). How Much Does Weather Control Fire Size and Intensity in The Mediterranean Region? Annales Geophysicae, 33(7), 931-939. https://doi.org/10.5194/angeo-33-
931-2015

6. Guswanto, \& Heriyanto, E. (2009). Operational Weather Systems for National Fire Danger Rating. Jurnal Meteorologi \& Geofisika, 10(2), 7787

7. Wagner, C. E. Van, Forest, P., \& Station, E. (1974). Structure of the Canadian Canadian Forestry Service Publication. Ottawa

8. De Jong, M. C., Wooster, M. J., Kitchen, K., Manley, C., Gazzard, R., \& McCall, F. F. (2016). Calibration and Evaluation of The Canadian Forest Fire Weather Index (FWI) System For Improved Wildland Fire Danger Rating in The United Kingdom. Natural Hazards and Earth System Sciences, 16(5), 1217-1237. https://doi.org/10.5194/nhess-161217-2016

9. Heriyanto, E., Syaufina, L., \& Effendy, S. (2014). Perbandingan Indeks Fine Fuel Moisture Code ( Ffmc ) Dan Fire Weather Index ( Fwi ) Pada Sistem Peringkat Bahaya Kebakaran Hutan / Lahan Luaran Wrf Dengan Observasi ( 


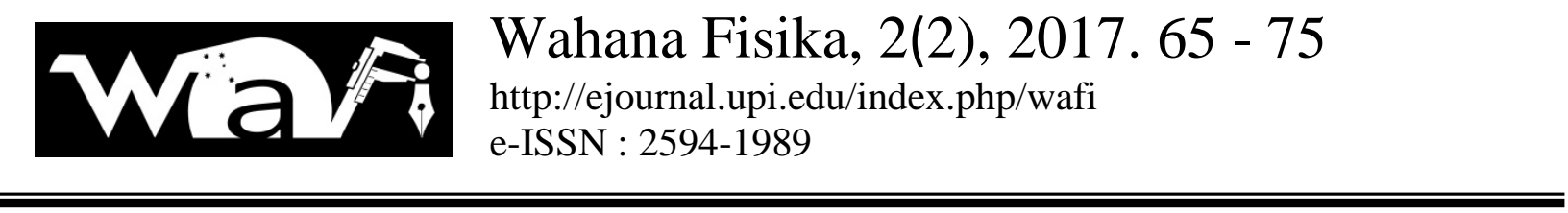

Periode: Juni - Agustus 2013 ). 15(2), 119-127

Jurnal Meteorologi Dan Geofisika, 